\title{
A Collaborative Framework for a Cross-Institutional Assessment to Shape Future IT Professionals
}

\section{Anne Venables and Grace Tan Victoria University, Melbourne, Victoria, Australia}

anne.venables@vu.edu.au grace.tan@vu.edu.au

\author{
Sunam Pradhan \\ Federation University \\ Australia, Victoria, Australia
}

s.pradhan@federation.edu.au

\begin{abstract}
There is a need for Information Technology (IT) students to develop an awareness of current IT business practice and the role of IT plays in the broader society, together with an appreciation of some of the ethical dilemmas, security challenges, and threats to privacy that the application of IT can raise. In fact, an understanding of these concepts is underlined by professional bodies through their accreditation requirements for university IT programs. Yet, students have limited professional experience and may have difficulty in relating to the challenges posed by the use of IT in the wider community; therefore it is incumbent on undergraduate programs to provide learning experiences that foster students' professional growth in these areas.

The difficulty for IT educators is how to develop in their students an understanding of current IT industry practice coupled with a broader awareness of the impact of their discipline on society. A discussion on how best to address this difficulty brought academics from Victoria University and University of Ballarat together. The outcome was a proposal for a joint teaching collaboration that centered on a common assessment formative task for students enrolled in each institution's professional development units. This paper outlines the motivation and rationale for the proposal and it details the collaborative framework essential to support an across-institutional assessment task. The paper relates the framework to realize the creation of the assessment at both universities to improve students' IT professional development.
\end{abstract}

Keywords: information technology (IT), collaborative framework, across-institution, formative assessment, professional skills development

Material published as part of this publication, either on-line or in print, is copyrighted by the Informing Science Institute. Permission to make digital or paper copy of part or all of these works for personal or classroom use is granted without fee provided that the copies are not made or distributed for profit or commercial advantage AND that copies 1) bear this notice in full and 2) give the full citation on the first page. It is permissible to abstract these works so long as credit is given. To copy in all other cases or to republish or to post on a server or to redistribute to lists requires specific permission and payment of a fee. Contact Publisher@InformingScience.org to request redistribution permission.

\section{Introduction}

Information Technology (IT) has profoundly changed the way we live; it permeates into every aspect of our personal lives by affecting how we communicate and interact with one another, locally and globally. Business has been greatly impacted thanks to widening accessibility of the Internet; the increas- 
ing proliferation of applications, including mobile, has seen transformations in many aspects of shopping, tourism, banking and hospitality. The advent of these new technologies and the increased ability of computer systems to store and process large amounts of data available on a global scale have brought new threats to data security and privacy that now transcend national borders (Poulos, 2012; Rogerson \& Prior, 2008).

In Australia, IT has become increasingly important at a national level, where the sector employs over half a million workers contributing nearly $8 \%$ of the Australian GDP. Each year, approximately 4,300 IT graduates enter the workforce (ACS, 2012a; Australian Government, Workforce and Productivity Agency, 2012). It is an industry expectation that new graduates are equipped with a suite of professional behaviors inclusive of the necessary technical competencies and supporting 'soft' skills, that is, teamwork, leadership, communication and people skills, encompassed in a broader appreciation of the discipline and its practice. It is incumbent upon IT degree programs to adequately prepare their students in all of these aspects, and this matter is underlined by the professional body, the Australian Computer Society (ACS), which mandates the acquisition of each of these competencies through their requirements for professional accreditations of IT degree programs (ACS, 2013).

Most IT programs adequately develop the technical skills necessary to prepare their students for the rapidly evolving IT industry. The greater difficulty for educators is how to inculcate the desired soft skills practice and how to develop in their students an understanding of current IT industry practice coupled with a broader awareness of the impact of their discipline on society. This challenge brought about a discussion on how best to address this difficulty between academics from Victoria University and University of Ballarat. This paper describes the outcome of this discussion, being a proposal and a framework to support a joint teaching collaboration that centered on a common formative assessment task for students enrolled in each institution's professional development units. The rationale for the collaboration is presented next.

\section{The Rationale}

The ACS lists professional knowledge as one of six building blocks of fundamental knowledge shared by all IT professionals, and thus its inclusion is necessary in any Australian accredited IT program. Professional knowledge compasses ethics, societal and privacy issues, professionalism and an appreciation of the status of the discipline, teamwork concepts and interpersonal communication skills (ACS, 2012b). As a consequence, the ACS accredited IT programs at University of Ballarat and Victoria University have teaching materials to ensure their students are equipped with the mandated professional knowledge skill set.

Historically, the establishment of co-institutional teaching collaborations has been driven by the need to offer 'boutique' units of study at participating institutions. In these cases, the units were either very narrow in expertise (e.g., astrophysics), or each institution did not have sufficient resources or sufficient student enrolment to offer the unit (As examples, Ferrario, Loy \& Lattanzio, n.d.; Knox, 1997). This was not the impetus for our teaching collaboration.

Our teaching collaboration was driven by two strong needs. The first need was to broaden our students' understanding of current professional IT business practices and an appreciation of IT and their impact on societal issues. The second need was the desire to incorporate quality assurance in our respective programs. As others have reported, the sharing of expertise and procedures relating to undergraduate IT courses helps strengthen ties between institutions (Australian Government, 2013; Brereton et al., 2000).

The collaboration would address these needs through a learning strategy that would allow the students the opportunity to interact with peers at another institution so that they may develop further insights into professional practice that would not have been obtained otherwise. In addition, it 
would be a mechanism to foster quality assurance of the two professional development units: Security, Privacy and Ethics at Victoria University and Professional Development at the University of Ballarat. The Security, Privacy and Ethics unit introduces topical, contemporary, and often controversial issues and it affords students the opportunity to examine ethical dilemmas, security challenges and privacy concerns brought about through the use of IT in society. Professional Development focuses on professional practice skills, including project management, and ethical and societal issues in IT.

In their discussions, academics from both institutions recognized the power of assessment to motivate students and drive learning outcomes (Boud \& Falchikov, 2007). It was noted that formative assessment would provide opportunities for students to learn through the process of undertaking an assigned task (Black and William, 2009). Such tasks capitalize on processes in learning and teaching, being the establishment of where the students are in their learning, where they are going, and what needs to be done to get them there (Ramaprasad, 1983; William and Thompson, 2007). To accomplish this, it was agreed that a formative assessment task would be designed centered around an investigation of real-life IT business practice and professional behaviors, particularly in response to ethical dilemmas, security challenges and threats to privacy. Essentially, industry involvement would be required. Therefore, the learning experience should provide a mechanism for students to gain an 'industry-informed' understanding of the importance of professional IT skills and, through working with students from their partner institution and opportunities to improve their interpersonal and communication skills. A formative assessment task drawing upon common topics in the two professional development units was to be coauthored by the teaching academics.

\section{The Collaboration Framework}

To establish and enact any cross-institute common assessment task, it is necessary to establish a collaboration framework to support and guide the academics involved. The framework will provide focus on the overall purpose of the collaboration; it helps participants to visualize and clarify what needs to be done, it defines roles and responsibilities for participations and it outlines the milestones to be achieved. The framework is comprised of three primary stages: initiating connections, establishing collaborative protocols and designing the common assessment task, as shown in Table 1.

\section{Stage 1: Initiating Connections}

The first step in establishing a teaching collaboration involving a common assessment across institutions is to investigate similar program offerings. The exploration needs to look for commonalities in content and the intent of individual units of study. Necessarily for the investigation to bear fruit, a champion at each participating institution is to be identified in order for such a collaboration to work through to completion. Indeed, this is the most crucial precondition in forecasting the success, or otherwise, of this type of initiative.

At the conclusion of this stage, a list of appropriate units of study will be identified together with a set of learning objectives for which the assessment will target. This will result in the selection of the most appropriate unit of study for implementing the collaboration at each institute.

\section{Stage 2: Establishing Collaborative Protocols}

Once the educational goals and learning outcomes have been elucidated, the teaching materials of the nominated units of study are to be exchanged and examined in detail looking for areas of overlap in content. A common assessment task by its nature should incorporate at least some of the identified areas of overlap to be relevant to both units. Next, a group of collaborative proto- 
cols are to be decided to cover the mechanics of the assessment. This step is necessary to ensure that each institution's requirements for assessment will be met, the timing of the assessment is appropriate, the roles and responsibilities for participants are clearly defined and the physical and organisational constraints can be met.

Table 1: The collaborative learning framework for cross-institutional assessment

\begin{tabular}{|c|c|c|}
\hline \multicolumn{2}{|l|}{ Stage } & \multirow[b]{2}{*}{$\begin{array}{l}\text { Outcomes } \\
\text { A list of possible units of study that } \\
\text { develop professional IT practice at re- } \\
\text { spective institutions } \\
\text { A list of learning outcomes to be } \\
\text { achieved through a common assessment } \\
\text { Selection of the appropriate unit of } \\
\text { study at each institute }\end{array}$} \\
\hline 1. Initiating connections & $\begin{array}{l}\text { Stage 1a: Research IT pro- } \\
\text { grams at participating insti- } \\
\text { tutes } \\
\text { Stage 1b: Identify common } \\
\text { educational goals }\end{array}$ & \\
\hline \multirow{2}{*}{$\begin{array}{l}\text { 2. Establishing collaborative } \\
\text { protocols }\end{array}$} & Stage 2a: Getting together & A list of common topics \\
\hline & $\begin{array}{l}\text { Stage } 2 \mathrm{~b} \text { : Defining and setting } \\
\text { protocol parameters }\end{array}$ & $\begin{array}{l}\text { Agreed collaborative protocols, such as, } \\
\text { timelines, roles and responsibilities }\end{array}$ \\
\hline \multirow[t]{2}{*}{$\begin{array}{l}\text { 3. Designing a common } \\
\text { assessment task }\end{array}$} & $\begin{array}{l}\text { Stage 3a: Brainstorm and re- } \\
\text { search assessment task }\end{array}$ & $\begin{array}{l}\text { A selection of possible assessment types } \\
\text { Selection of the most suitable assess- } \\
\text { ment type for both institutions }\end{array}$ \\
\hline & $\begin{array}{l}\text { Stage 3b: Design and develop } \\
\text { assessment components in- } \\
\text { cluding weightings, tasks and } \\
\text { due dates }\end{array}$ & $\begin{array}{l}\text { A benchmarked assessment specifica- } \\
\text { tion }\end{array}$ \\
\hline
\end{tabular}

In setting the protocol parameters, the following are of primary concern:

- Timing of the units - the units need to be closely temporal so that students from both institutes are able to participate in the common assessment as part of their normal semester studies;

- Sequencing of topics - backgrounding topics need to be covered before distribution of assessment to students in order that learning outcomes can be achieved; and,

- Authorship of assessment specification - ideally, teaching academics from both institutions should decide and set the assessment task.

By the end of this stage, a list of common topics to both units of study will be identified and a set of agreed protocols will be decided prior to designing a common assessment task.

\section{Stage 3: Designing a Common Assessment Task}

The success, or otherwise, of a cross-institution collaborative effort rests on the design and implementation of an assessment task that is meaningful and worthwhile to both IT programs. The effort invested at this stage needs to be cognizant of this understanding. An inspection of possible assessment types appropriate to the task is to be made. The pros and cons of each type should be discussed to arrive at a suitable candidate assessment type for implementation in both units of study.

Once agreed upon, the content and the technicalities of the assessment task are to be crafted. Firstly, the overall credit value of the task should carry the same proportional weight in both 
units. Secondly, the number of components and their contribution to assessment weight are to be decided. Consideration should be made so that each component of the assessment targets the various learning outcomes identified in Stage 1. For instance if improved communication skills are listed as a learning outcome, communications practice should be incorporated and measured through an assessment component.

The final outcome of this stage will be an assessment specification which has been benchmarked across institutions.

\section{Realizing the Collaboration Framework}

The establishment of the collaboration framework came about through the process of enacting a meaningful assessment task at both institutes and the need to guide participants throughout the journey. The details of our implementation are related below.

\section{Stage 1: Initiating Connections}

Often times, conversations between IT academics from different universities invariably gravitate to teaching matters and discussing commonalities and differences between programs and teaching and learning approaches. Such a conversation between academics at Victoria University and University of Ballarat revolved around the common desire to broaden student understandings of IT professional practices and the shared need to incorporate benchmarking strategies into teaching practices.

Students studying IT undergraduate programs at Victoria University and at University of Ballarat have few opportunities to network with IT practitioners; such opportunities would afford students a chance to gain an insight into IT business practices and some understanding of the important security, privacy and ethical issues encountered in the practice of IT. A cross-institute assessment for students undertaking professional development units of study at both locations was seen as a suitable vehicle to address these objectives. Additionally, academics from both institutes saw the proposed teaching strategy as a mechanism to ensure students practice in communication and networking skills with peers from the partner institution. In this partnership, students would need to incorporate solutions to overcome the challenge posed by the physical distance between each university, being located approximately 100 kilometres apart.

The Security, Privacy and Ethics unit at Victoria University and the Professional Development unit at University of Ballarat were identified as the best fit for the collaboration.

\section{Stage 2: Establishing Collaborative Protocols}

Meetings between the teaching academics involved in the selected professional development units undertook close examination of the teaching materials of both units looking for areas of overlap in content. Details of the content and commonalities are provided in Table 2, where it can be seen that the two targeted units are relatively similar in intent (to cover the ACS requirements) but different in their foci. The Security, Privacy \& Ethics unit is particularly focused on the social aspects of IT and the impact of culture in the response to IT usage, whereas the Professional Development unit incorporates specific business and professional skills, such as team skills and negotiation practice, report writing and presentations. The topics in Table 2 are listed in their teaching order. 
Table 2: Topics of the professional development units at Victoria University and University of Ballarat showing commonalities

\begin{tabular}{|l|l|}
\hline \multicolumn{1}{|c|}{ Security, Privacy \& Ethics } & \multicolumn{1}{c|}{ Professional Development } \\
\hline Privacy & Ethical theories \\
Security & ACS code of ethics \& code of conduct \\
Social IT issues, digital divide, culture & Social issues \\
IT issues in the workplace & Legal issues of security \& privacy breaches \\
Ethics theories & Cyber crime \\
Professional ethics \& the ACS & Intellectual property \\
Web 2.0 and social networking & Social \\
Intellectual property & Project management \\
& Business \& professional practice skills \\
\hline
\end{tabular}

Initial discussions were primarily concerned with the timelines of these units; the University of Ballarat offers their unit on a semester basis whereas Victoria University only runs their unit annually. Therefore, for practical reasons the implementation of the cross-institute assessment task would need to wait until a common scheduling of units. The respective sequencing of the unit topics should ensure that students have sufficient background information so that they are well prepared to undertake the formative assessment. Finally, the authors of this paper were identified as the participants of the collaboration and they prepared themselves for designing and writing of a common assessment task.

\section{Stage 3: Designing a Common Assessment Task}

Traditionally in the running of each IT unit, two formative assessment tasks are typically given. For the collaborative assessment it was decided that only one, the second, assessment task would be shared. It was agreed that this assessment task would centre on professional practice, including the application of the ACS Code of Ethics to problems of security, privacy and ethical issues in the IT workplace. It would be the responsibility of each participant to ensure that their respective institution's requirements for assessment would be met.

The learning outcomes identified in Stage 1 formed the foundation of the common assessment task. The learning outcomes were to improve student abilities in:

A. Interpersonal communication skills, such as networking, team and negotiation skills;

B. Understanding some of the important security, privacy and ethical issues encountered in IT organizations;

C. Appreciation of the context of business decision-making and the issues of managing people to perform the required tasks effectively and efficiently;

D. Evaluation of the relevance of the ACS ethical framework in the IT business environment; and,

E. Presentation skills.

These learning outcomes would be realized through a 'novice meets expert' experience, where teams of students would interview someone who has a leadership role within an IT organization/department. Interview questions would be researched by students, with questions taken from two of the following topics: security challenges, privacy threats, ethical dilemmas, social networking in the workplace, application of the ACS Code of Ethics, IT project management, employee performance and conflict management. The selected topics encompass materials from both professional unit offerings, so the requirement that students need to research and decide their topics from these, encourages cross-fertilization of perspective that students from each institute would not gain otherwise. 
To guide students in their learning, the assessment task is scaffolded into three parts, being interview preparation, undertaking of the interview, its audio recording and written report, and participation in a final presentation. Table 3 relates each assessment part to the learning outcomes being addressed.

Table 3: Scaffolded assessment tasks

\begin{tabular}{|ll|l|}
\hline \multicolumn{1}{|c|}{ Assessment Part } & \multicolumn{1}{c|}{ Addressed Learning Outcomes } \\
\hline 1. & Interview preparation & $\mathrm{A}, \mathrm{B}$ \\
\hline 2. & $\begin{array}{l}\text { Interview, audio recording and written } \\
\text { report }\end{array}$ & $\mathrm{A}, \mathrm{B}, \mathrm{C}, \mathrm{D}$ \\
\hline 3. & Presentation & $\mathrm{A}, \mathrm{B}, \mathrm{C}, \mathrm{D}, \mathrm{E}$ \\
\hline
\end{tabular}

For the assessment, teams of four (two students per institution) will be assigned by teaching staff. The responsibility for making contact between team members will be that of the students. Teams need to source their own interviewee, conduct a group interview, prepare a written report of the interview and lessons learnt, and present collectively at a joint-University function.

\section{At this stage...}

Plans are afoot for the running of the common assessment task in next offering of both professional development units, where the assessment will replace the individual second assessment tasks currently found in both units. A joint-University function will be arranged to enable crossinstitute teams to present their understandings and findings derived from their interviews. To facilitate this, students and staff from Victoria University will travel to the University of Ballarat for an all-day visit. Presentations will be assessed by academics from both universities, as are all individual components of the assessment. This plan for joint assessment will enable moderation across all cohorts of students, ensuring grading consistency for each assessment part. For quality assurance and improvement, feedback from students will be collected and opportunities organized to collect the reflections of all participating staff. Outcomes of the upcoming implementation incorporating feedback from participants will be reported.

\section{Conclusion}

The drivers for our teaching collaboration were twofold. Firstly, we wished to provide a learning experience that would help students gain an industry-informed understanding of the importance of professional ICT skills and opportunities to improve their interpersonal and communication skills through cross-institutional student teamwork. Secondly, we saw our joint teaching initiative as a means to achieve external referencing, monitoring, review and improvement.

The framework presented in this paper could well be adopted by other institutions seeking to improve IT professional skills in student learning outcomes. In these cases, institutional customisation may be necessary and certainly worthwhile. Our experiences to date in creating a crossinstitute assessment have been valuable in informing and benchmarking our teaching practices.

\section{Acknowledgement}

The development of a collaborative framework and the design of a common assessment task outlined in this article have been supported by a Australian Council of Deans of ICT teaching grant. 


\section{References}

Australian Computer Society. (2013). ACS certification guidelines, 2013. Retrieved 18 October 2013 from https://www.acs.org.au/ data/assets/pdf file/0004/16762/ACS-CertificationGuidelines 19 March 2013 v2.4.pdf

Australian Computer Society. (2012a). 2012 Australian ICT statistical compendium. Retrieved 18 October, 2013 from http://www.acs.org.au/_data/assets/pdf_file/0014/13541/2012_Statcompendium_final_web.pdf

Australian Computer Society. (2012b). The ICT profession body of knowledge. Retrieved 18 October 2013 from http://www.acs.org.au/_ data/assets/pdf_file/0007/7792/The-ICT-Profession-Body-ofKnowledge.pdf

Australian Government. (2013). Higher Education Standards Panel, Communique Number 8- May 2013. Retrieved 18 October, 2013 from http://www.hestandards.gov.au/sites/default/files/CommuniqueNumber8-HEStandards.pdf

Australian Government, Workforce and Productivity Agency. (2012). ICT skills in the workplace forum: Parliament House. Overview of the ICT workforce. Presentation, 21 November 2012. Retrieved 18 October, 2013 from http://ict-industry-reports.com/wp-content/uploads/sites/4/2013/07/2012-ICT-SkillsForum-Presentation-AWPA-Nov-2012.pdf

Brereton, O., Lees, S., Bedson, R., Bodyreff, C., Drummond, S., Layzell, P. Macauly, L., \& Young, R. (2000). Student collaboration across universities: A case study in software engineering. Proceedings of the Conference on Software Engineering Education and Training, 76-86.

Black, P., \& William, D. (2009). Developing the theory of formative assessment. Educational Assessment, Evaluation and Accountability, 21, 5-31.

Boud, D., \& Falchikov, N. (Eds.). (2007). Rethinking assessment in higher education: Learning for the longer term. London: Routledge.

Ferrario, L., Loy. R., \& Lattanzio, J. (n.d). Piloting a cross-institutional collaborative approach to honours education in theoretical astrophysics.

Knox, D. (1997). A review of the use of video-conferencing for actuarial education- A three-year case study. Distance Education, 18(2).

Poulos, T. (2012). EC data privacy rules - Like a cat chasing its tail. Online blog. Retrieved 20 October 2012 from: http://www.telecomasia.net/blog/content/ec-data-privacy-rules-cat-chasing-its-tail?

Ramaprasad, A. (1983). On the definition of feedback. Behavioral Science, 28, 4-13.

Rogerson, S., \& Prior, M. (2008). Is IT ethical? The ETHICOMP survey of professional practice. IMIS Journal, 18(1). Retrieved January, 2012 from http://www.ccsr.cse.dmu.ac.uk/resources/general/ethicol/Ecv18no1.html

Wiliam, D., \& Thompson, M. (2007). Integrating assessment with instruction: What will it take to make it work? In C. A. Dwyer (Ed.), The future of assessment: Shaping teaching and learning (pp. 53-82). Mahwah, NJ: Erlbaum. 


\section{Biographies}

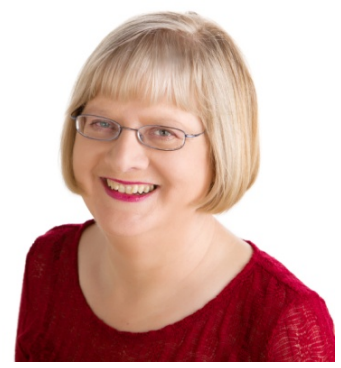

Anne Venables lectures in Computer Science and Information Technology at Victoria University, Melbourne, Australia. She has research and teaching interests in innovations in computing education and the application of intelligent systems in biological systems.

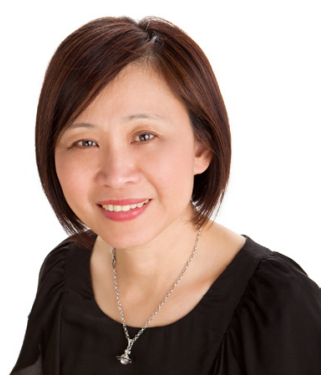

Grace Tan is a senior lecturer in Information Technology at Victoria University, Melbourne, Australia. Her research interests include investigations of innovative teaching methods, the development of graduate attributes, and information technology curricula design and Grace has published in these areas.

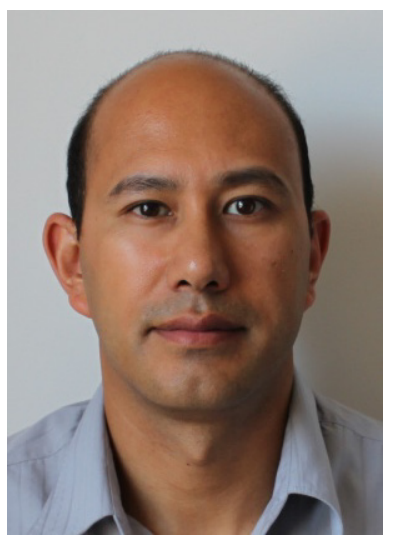

Sunam Pradhan is a lecturer with the School of Science, Information Technology and Engineering at Federation University (previously known as University of Ballarat), Victoria, Australia. His research interests are in mobile and web technologies, as well as educational technology. He is a member and Certified Professional (CP) of the Australian Computer Society (ACS). 